Gut, 1979, 20, 489-492

\title{
Cyclic AMP and cyclic GMP levels in human colonic mucosa before and during chenodeoxycholic acid therapy
}

\author{
G. R. CORAZZAin, R. CICCARELli, F. CACIAGLI, AND G. GASBARRINI \\ From the Institutes of Medical Pathology and Pharmacology, Chieti University, Chieti, Italy
}

SUMMARY Previous experimental studies suggest that bile salt-induced colonic fluid secretion is mediated by adenosine $3^{\prime}: 5^{\prime}$-phosphate (cyclic AMP). Two biopsy specimens of colonic mucosa were obtained endoscopically before and after different periods of therapy (five, 10, or 15 days), from each of 21 patients receiving chenodeoxycholic acid. A rise of cyclic AMP intracellular levels was found, but only after five and 10 days of treatment was the increase statistically significant when compared with basal levels. Similar changes were observed for guanosine $3^{\prime}: 5^{\prime}$-phosphate (cyclic GMP), but percentage increases were higher than for cyclic AMP. Initial diarrhoea disappeared spontaneously, and at 15 days the levels of both cyclic nucleotides were not significantly different from basal levels. Our findings suggest that colonic adaptation to increase in luminal bile salt levels is related to changes in intracellular levels of cyclic nucleotides and support the hypothesis that not only cyclic AMP, but also cyclic GMP may play an important role in producing bile salt-induced diarrhoea in man.

The presence of an abnormal amount of bile salts within the colon leads to a diarrhoeic syndrome, so called 'cholerheic enteropathy' (Hofmann, 1967). Analogous changes are frequently seen as sideeffects in patients treated with chenodeoxycholic acid (CDCA) (Bell et al., 1972; Danzinger et al., 1972; Iser et al., 1975; Barbara et al., 1976). Mok et al. (1974) were the first to demonstrate that such effects are dose-related.

Experimental observations in animals (Mekhjian and Phillips, 1970) and humans (Mekhjian et al., 1971) confirm that dihydroxy bile salts, mostly unconjugated (Forth et al., 1966), promote movement of water and electrolytes across the colonic mucosa. Binder et al. (1975) suggest that adenosine $3^{\prime}: 5^{\prime}$ phosphate (cyclic AMP) is the 'mediator' of bile salt-induced fluid secretion in rat colon in vivo. They observed that significantly raised intracellular levels of cyclic AMP occurred with a parallel increase of fluid secretion after incubation with taurochenodeoxycholic acid. The increased intracellular concentration of cyclic AMP, induced by bile salts in

\footnotetext{
${ }^{1}$ Address for correspondence: Dr G. R. Corazza, University Department of Medicine, St James's Hospital, Leeds LS9 7TF, England.
}

Received for publication 17 January 1979 colonic mucosa, seems to be a consequence of adenylate cyclase stimulation rather than phosphodiesterase inhibition (Conley et al., 1976). The aim of our investigation was to verify the possible role of cyclic AMP in producing diarrhoea as a side-effect of chenodeoxycholic acid treatment in patients with cholesterol gallstones, and to study simultaneous changes in intracellular guanosine $3^{\prime}: 5^{\prime}$-phosphate (cyclic GMP).

\section{Methods}

This study was carried out on 21 patients (nine men and 12 women; age range 27-52 years) with radiolucent gallstones and without previous clinical symptoms of organic or functional colon disease and with previously normal bowel habit.

Each patient was treated with chenodeoxycholic acid (CDCA), given orally in doses of $15 \mathrm{mg} / \mathrm{kg}$ body weight/day. Biopsy samples of colonic mucosa were obtained during colonoscopy from the middle third of the descending colon. Histology confirmed that the tissue comprised colonic mucosa only. A control sample was taken from each patient 24 hours before the treatment started. The patients were randomly allocated to three groups of seven subjects. The second sample was obtained from the first group 
after five days of treatment, from the second group after 10 days of treatment, and from the third group after 15 days of treatment.

Informed consent was obtained from each patient after full explanation and the investigation was approved by the local Ethical Committee. Samples were immediately frozen in liquid nitrogen for $30-60$ seconds. Then the sample was immersed in $6 \%$ perchloric acid and, after homogenisation and centrifugation $\left(18000 \mathrm{rpm}, 30 \mathrm{~min}, 0-4^{\circ} \mathrm{C}\right), 1 \mathrm{ml}$ neutralised supernatant ( $\mathrm{pH}$ 6.8-7.2) was purified by chromatography on Bio-Rad AG-1 X8 columns, formate form (200-400 mesh), as proposed by Frandsen and Krishna (1976). Cyclic AMP was eluted with $10 \mathrm{ml} 2 \mathrm{~N}$ formic acid and the cyclic GMP was eluted with $10 \mathrm{ml} 4 \mathrm{~N}$ formic acid.

After drying, the radioimmunoassay of cyclic AMP and cyclic GMP was performed, as described by Steiner et al. (1972), using kits obtained commercially (Schwarz/Mann Div., Becton Dickinson \& Co., Orangeburg, N.Y.). Radioactivity was determined as cpm in a Packard Autogamma counter (Packard Instruments Co., Inc., Downers Grove, IIl.) and expressed as $\mathrm{pmol} / \mathrm{mg}$ of tissue proteins. The quantity of mucosal proteins was determined with the Folin phenol reagent method (Lowry et al., 1951).

The results were expressed as mean \pm SEM for each nucleotide and statistical evaluation was performed using Student's $t$ test and the paired $t$ test.

For each patient the number of stools was counted in order to assess the effect of CDCA treatment on bowel habit; diarrhoea was defined arbitrarily as two or more loose stools per day in patients who had previously a normal bowel habit (Mok et al., 1974).

\section{Results}

There was little variation in basal levels of intracellular cyclic AMP in the 21 patients (mean value $22 \cdot 28 \pm 0.707 \mathrm{pmol} / \mathrm{mg}$ ). There were no significant differences between mean levels in the three groups (Table 1).

Table 1 Mean ( \pm SEM) cyclic AMP mucosal levels ( pmol/mg of mucosal protein) before and after various lengths of time on treatment with CDCA in three groups (seven patients in each group)

\begin{tabular}{lccc}
\hline Treatment & & & \\
\hline Before & After 5 days & After 10 days & After 15 days \\
\hline $19.86 \pm 0.958$ & $31.61 \pm 0.905^{*}$ & & \\
$22.75 \pm 1.428$ & & $29.67 \pm 1.866^{*}$ & \\
$24.21 \pm 0.644$ & & & $25.65 \pm 0.40$ \\
\hline
\end{tabular}

*Significantly different from pretreatment values $(\mathrm{P}<0.01$; paired $t$ test).
Mean basal level of intracellular cyclic GMP was $3.91 \pm 0.248 \mathrm{pmol} / \mathrm{mg}$. Although the third group of patients had higher mean basal level than the first and second groups, there were no significant differences between the groups (Table 2).

Table 2 Mean $( \pm S E M)$ cyclic GMP mucosal levels (pmol/mg of mucosal protein) before and after various lengths of time on treatment with CDCA in three groups (seven patients in each group)

\begin{tabular}{lccc}
\hline Treatment & & & \\
\hline Before & After 5 days & After 10 days & After 15 days \\
\hline $3.69 \pm 0.273$ & $8.15 \pm 1.219^{*}$ & & \\
$3.35 \pm 0.492$ & & $6.20 \pm 1.098^{*}$ & \\
$4.69 \pm 0.371$ & & & $5.98 \pm 0.336$ \\
\hline
\end{tabular}

*Significantly different from pretreatment values $(\mathrm{P}<0.01$; paired $t$ test).

After CDCA treatment mean intracellular cyclic AMP and cyclic GMP levels were higher than basal levels in each group of patients (Tables 1 and 2). The maximal increase of both cyclic nucleotides was present after five days of therapy $(31.61 \pm 0.905$ $\mathrm{pmol} / \mathrm{mg}$ cAMP; $8.15 \pm 1.219 \mathrm{pmol} / \mathrm{mg}$ cGMP). The increase was of a lesser degree after 10 days and less still after 15 days. In particular, the difference between basal and post-treatment levels for both nucleotides was statistically significant only after five and 10 days (Tables 1 and 2), whereas intracellular levels of cyclic AMP and cyclic GMP were not significantly different from basal levels after 15 days of treatment.

Clinically no side-effects, except bowel habit changes, usually diarrhoea, were observed. The number of loose stools per day is shown in Table 3 along with the percentage increase of both cyclic nucleotides relative to basal levels. Three patients had persistent constipation and low levels of cGMP.

\section{Discussion}

Recent experiments suggest that cyclic AMP has a role as 'mediator' in promoting bile salt-induced colonic fluid secretion (Binder et al., 1975; Conley et al., 1976). In patients treated with CDCA, a temporary diarrhoea is often observed (Bell et al., 1972; Danzinger et al., 1972; Iser et al., 1975; Barbara et al., 1976).

Our results confirm that, in human colonic mucosa, treatment with CDCA is associated with an increase in intracellular levels of cyclic AMP. Such an increase remains statistically significant with respect to controls even at $\mathbf{1 0}$ days of treatment when there is no more clinically important diarrhoea. This chronological disparity between the clinical symptoms and biochemical data indirectly suggests that 
Table 3 Effects of treatment with chenodeoxycholic acid on cyclic nucleotide levels and bowel habit

\begin{tabular}{|c|c|c|c|c|}
\hline \multirow[t]{2}{*}{ Patients } & \multirow[t]{2}{*}{ Days of treatment } & \multicolumn{2}{|c|}{$\begin{array}{l}\text { Post-treatment \% increase of cyclic } \\
\text { nucleotides relative to basal levels }\end{array}$} & \multirow[t]{2}{*}{ Number of loose stools* } \\
\hline & & $c A M P$ & $c G M P$ & \\
\hline 1 & 5 & $50 \cdot 36$ & $144 \cdot 90$ & 10 \\
\hline 2 & 5 & 68.03 & 24.52 & C \\
\hline 3 & 5 & 46.21 & $5 \cdot 15$ & C \\
\hline 4 & 5 & 70.81 & $149 \cdot 20$ & 10 \\
\hline 5 & 5 & 67.91 & $164 \cdot 55$ & 7 \\
\hline 6 & 5 & 37.03 & $148 \cdot 14$ & 9 \\
\hline 7 & 5 & 83.62 & 173.67 & 11 \\
\hline 8 & 10 & $41 \cdot 34$ & 202.97 & 3 \\
\hline 9 & 10 & 30.05 & 104.98 & 1 \\
\hline 10 & 10 & $27 \cdot 83$ & 12.50 & C \\
\hline 11 & 10 & 14.06 & $-17 \cdot 46$ & FS \\
\hline 12 & 10 & 30.44 & $159 \cdot 46$ & 2 \\
\hline 13 & 10 & $28 \cdot 45$ & 114.59 & 2 \\
\hline 14 & 10 & $42 \cdot 14$ & $44 \cdot 00$ & 1 \\
\hline 15 & 15 & 4.59 & 57.50 & 2 \\
\hline 16 & 15 & 8.60 & -8.50 & FS \\
\hline 17 & 15 & $-8 \cdot 11$ & $17 \cdot 32$ & FS \\
\hline 18 & 15 & 24.07 & 17.98 & FS \\
\hline 19 & 15 & 4.63 & $55 \cdot 16$ & 1 \\
\hline 20 & 15 & 3.57 & 20.00 & FS \\
\hline 21 & 15 & $7 \cdot 76$ & 56.80 & FS \\
\hline
\end{tabular}

*The evaluation refers to the day of the second biopsy and the day before and after it. C: constipation. FS: formed stools.

the production of fluid secretion cannot be related solely to variations in intracellular levels of cyclic AMP. Our experiments indicate that there is also a significant increase in cyclic GMP intracellular levels after five and 10 days of treatment. Such an increase, which is greater in percentage terms than for cyclic AMP, may be physiopathologically important. Persistent constipation in three patients with low cyclic GMP intracellular levels, even in the presence of a conspicuous increase of cyclic AMP, suggests that the side-effect of diarrhoea occurs as a consequence of a parallel considerable increase of both nucleotides.

Interestingly, when CDCA therapy was continued for 15 days, the increase in intracellular levels of both cyclic nucleotides was less than at 10 days. This experimental observation relates to the clinical finding that in our patients the diarrhoea tends to disappear spontaneously during treatment. The adaptation of the colonic mucosa to stimulation by bile salts has been demonstrated recently in a rat experimental model by Scarpello et al. (1978). In this model the cathartic effect of added bile salts was not present in rats which had previously undergone ileal resection, causing increased colonic bile salt levels.

Our results could be explained by a single mechanism. The increase of both cyclic nucleotides caused by the activation of the respective cyclase systems, could be the expression of simultaneous stimulation of their receptors.
Wald et al. (1977), in their observations concerning the effects of indomethacin on cholera enterotoxininduced secretion in rabbit jejunum, offer a confirmation of this hypothesis. Although indomethacin reduces intestinal secretion, it does not affect cyclic AMP levels, which remain considerably increased by cholera enterotoxin, suggesting that there is another cyclic AMP independent secretory mechanism; our study of bile salt-induced diarrhoea indicates that this mechanism may be the parallel activation of colonic cyclic GMP.

The simultaneous stimulation of both cyclase systems might lead to their subsequent reciprocal inhibition. It is known that when there is selective stimulation of a single cyclase system, such as in an inflammatory process, there is not only an increase of a single cyclic nucleotide, but at the same time a depression of the other nucleotides (Willoughby et al., 1975; Bertelli et al., 1976).

The spontaneous remission of CDCA-induced diarrhoea could, therefore, be explained by the reciprocal inhibition of the cyclase systems, related to their simultaneous and protracted activation.

We are grateful to Professor R. H. Dowling, London, for his valuable criticism.

\section{References}

Barbara, L., Roda, E., Roda, A., Sama, C., Festi, D., 
Mazzella, G., and Aldini, R. (1976). The medical treatment of cholesterol gallstones: experience with chenodeoxycholic acid. Digestion, 14, 209-219.

Bell, G. D., Whitney, B., and Dowling, R. H. (1972). Gallstone dissolution in man using chenodeoxycholic acid. Lancet, 2, 1213-1216.

Bertelli, A., Caciagli, F., and Schinetti, M. L. (1976). Kinins and inflammation: changes induced on the levels of cyclic nucleotides. In Kinins: Pharmacodynamics and Biological Roles, pp. 97-102. Edited by F. Sicuteri, W. Back, and G. L. Haberland. Plenum Press: New York.

Binder, H. J., Filburn, C., and Volpe, B. T. (1975). Bile salt alteration of colonic electrolyte transport: role of cyclic adenosine monophosphate. Gastroenterology, 68, 503-508.

Conley, D. R., Coyne, M. J., Bonorris, G. G., Chung, A., and Schoenfield, L. J., (1976). Bile acid stimulation of colonic adenylate cyclase and secretion in the rabbit. American Journal of Digestive Diseases, 21, 453-458.

Danzinger, R. G., Hofmann, A. F., Schoenfield, L. J., and Thistle, J. L. (1972). Dissolution of cholesterol gallstones by chenodeoxycholic acid. New England Journal of Medicine, 286, 1-8.

Forth, W., Rummel, W., and Glasner, H. (1966). Zur resorption shemmenden Wirkung von Gallensäuren. Naunyn-Schmiedebergs Archiv fur Experimentelle Pathologie und Pharmakologie, 254, 364-369.

Frandsen, E. K., and Krishna, G. (1976). A simple ultrasensitive method for the assay of cyclic AMP and cyclic GMP in tissues. Life Sciences, 18, 529-541.

Hofmann, A. F. (1967). The syndrome of ileal disease and the broken enterohepatic circulation: cholerheic enteropathy. Gastroenterology, 52, 752-757.

Iser, J. H., Dowling, R. H., Mok, H. Y. I., and Bell, G. D. (1975). Chenodeoxycholic acid treatment of gallstones. A follow-up report and analysis of factors influencing response to therapy. New England Journal of Medicine, 293, 378-383.

Lowry, O. H., Rosebrough, N. J., Farr, A. L., and Randall, R. J. (1951). Protein measurement with the Folin phenol reagent. Journal of Biological Chemistry, 193, 265-275.

Mekhjian, H. S., and Phillips, S. F. (1970). Perfusion of the canine colon with unconjugated bile acids: effect on water and electrolyte transport, morphology, and bile acid absorption. Gastroenterology, 59, 120-129.

Mekhjian, H. S., Phillips, S. F., and Hofmann, A. F. (1971). Colonic secretion of water and electrolytes induced by bile acids: perfusion studies in man. Journal of Clinical Investigation, 50, 1569-1577.

Mok, H. Y. I., Bell, G. D., and Dowling, R. H. (1974). Effects of different doses of chenodeoxycholic acid on bile lipid composition and on frequency of side-effects in patients with gallstones. Lancet, 2, 253-257.

Scarpello, J. H. B., Cary, B. A., and Sladen, G. E. (1978). Effects of ileal and caecal resection on the colon of the rat. Clinical Science and Molecular Medicine, 54, 241-249.

Steiner, A. L., Pagliara, A. S., Chase, L. R., and Kipnis, D. M. (1972). Radioimmunoassay for cyclic nucleotides. II Adenosine $3^{\prime}-5^{\prime}$ monophosphate and guanosine $3^{\prime}-5^{\prime}$ monophosphate in mammalian tissues and body fluids. Journal of Biological Chemistry, 247, 1114-1120.

Wald, A., Gotterer, G. S., Rajendra, G. R., Turjman, N. A., and Hendrix, T. R. (1977). Effect of indomethacin on cholera-induced fluid movement, unidirectional sodium fluxes, and intestinal cAMP. Gastroenterology, 72, 106-110.

Willoughby, D. A., Dunn, C. J., Yamamoto, S., Capasso, F., Deporter, D. A., and Giraud, J. P. (1975). Calcium pyrophosphate-induced pleurisy in rats: a new model of acute inflammation. Agents and Actions, 5, 35-39. 